\title{
Management of vaccination - related anaphylaxis
}

\author{
Ariyanto Harsono \\ Department of Child Health, Medical School, Airlangga University/Soetomo Hospital, Surabaya
}

\begin{abstract}
Anaphylaxis is a systemic, immediate hypersensitivity reaction due to $\lg E$ mediated immunologic release of mediators from mast cells and basophils. Features of severe condition are obstruction of the upper airway from tissue swelling, marked bronchospasm, and hypotension. In vaccination related anaphylaxis, optimal management begins with prevention: prevaccination screening including questions about possible allergy to any component of vaccine, and anticipation of anaphylaxis by observation at least 15 minutes following vaccination are very important. The essential treatment is prompt administration of adrenaline. Since hypotension is due to a shift of fluid from intravascular to extravascular space, the mainstay of treatment should be the restoration of intravascular volume. Since anaphylaxis can be biphasic administration of corticosteroid in preventing late phase reaction can be postulated. [Paediatr Indones 2001; 41:96-99]
\end{abstract}

Keywords: anaphylaxis, immunization, untoward effects

\begin{abstract}
ANAPHYLAXIS IS A SYSTEMIC, IMMEDIATE HYPERSENSITIVITY reaction due to $\operatorname{IgE}$ mediated immunologic release of mediators from mast cells and basophils. ${ }^{1}$ There is nothing that we do in health care intervention that is without risk. Some with high risk and others with minimal risk to the patient, and anaphylaxis is one of the high risk. Vaccines are no exception, whether they are manipulated natural infectious agents, detoxified products of natural agents or manufactured by modern genetic recombinant techniques, they all have some risks. ${ }^{2}$ Although the incidence of anaphylaxis post vaccination is rare, every vaccine provider should be able to recognize early in the beginning of the event and treat promptly to minimize fatal outcome.
\end{abstract}

Correspondence: Ariyanto Harsono, MD, Department of Child Health, medical Scool, Airlangga University - Soetomo Hospital, Jl. Prof. Moestopo 6-8, Surabaya, Indonesia. Tel. 62-31-5501693, Fax 5501748.

\section{Signs and symptoms}

During anaphylactic reaction, changes develop progressively over several inutes and typically involve multiple body systems, particularly the skin, respiration and circulation. The cardinal features of anaphylaxis include: itchy, urticarial rash sometimes prominent at the injection site. Progressive edema can also develop involving the face or mouth or other body parts. ${ }^{3}$ Respiratory symptoms such as sneezing coughing, wheezing, hoarseness or difficulty swallowing, possibly culminating in airway obstruction. ${ }^{1,3}$ Hypotension generally developing later in the process and possibly progressing to cause shock and prostration. ${ }^{3}$

It should be noted that cardiovascular collapse with shock can occur immediately without any cutaneous or respiratory symptoms. ${ }^{4}$ Patients with early or mild sign of anaphylaxis will typically have urticarial rash with some combination of sneezing, nasal congestion, tearing, coughing or facial flushing along with 
understandable anxiety. Features of severe disease include obstruction of the upper airway from tissue swelling, marked bronchospasm and hypotension.

Symptoms usually begin within 5 to 30 minutes when vaccine has been administered by injection. However, there can be a delay of an hour or more after oral administration, symptoms usually occur within the first 2 hours after ingestion but can be delayed for several hours. It is believed that there is a direct correlation between the immediacy of onset of symptoms and the severity of a given attack. The more rapid the onset, the more severe the episode.

An episode can abate and then exhibit a recrudescence several hours after symptoms have disappeared. This has been termed "biphasic anaphylaxis". 5 In addition, attacks can be protracted, persisting for over 24 hours. This is especially true for cardiovascular symptoms which can occur in spite of appropriate therapy. ${ }^{6}$ Death can occur at anytime during the course of protracted anaphylaxis.

Anaphylactic reactions must be distinguished from fainting (vasovagal syncope), anxiety and breath holding spells, which are common, benign reactions requiring only symptomatic treatment. ${ }^{3}$ The hallmarks of fainting are sudden onset of pallor, loss of consciousness and collapse to the ground, sometimes associated with brief clonic seizure activity. Recovery of consciousness occurs within 1-2 minutes of reaching recumbent position although pallor and sweating may persist for several more minutes. In contrast, sudden unconsciousness is hardly ever the presenting feature of anaphylaxis. ${ }^{2,3}$

\section{Prevention}

Anaphylactic reactions are an unavoidable aspect of the practice of medicine. Optimal management of anaphylaxis begins with prevention. Prevaccination screening should include questions about possible allergy to any component of the product being considered, including components present in small quantities in some vaccines such as antibiotics, stabilizer (such as gelatin) or contaminating proteins (e.g. in egg-derived vaccines such as measles and influenza)..$^{2,3}$

Since avoidance is not always possible, anticipation of anaphylaxis is the second step in optimal management. Most instances begin within 30 minutes af- ter vaccination, shorter onset intervals are associated with more severe reactions. Vaccine recipients should therefore be kept under supervision for at least 15 minutes following vaccination. Thirty minutes is a safer observation period when there is a specific concern about possible vaccine allergy.

\section{Treatment}

Rapid recognition and treatment are essential. It is believed that prompt initiation of therapy prevents fatalities. The priority is prompt administration of adrenaline (epinephrine) which sho sld not be delayed if earlier steps cannot be completed quickly. Speedy intervention is of paramount importance: failure to use adrenaline promptly is more datıgerous than using it improperly. Every vaccinator shou $\mathrm{d}$ have immediate access to an anaphylaxis kit conta ning several vials of adrenaline with appropriate shelf life dating and injection supplies (Table 1 ). The adrenaline dose should be carefully determined; calculation based on body weight is preferred when pitient's weight is known. A dose of $0.01 \mathrm{mg} / \mathrm{kg}$ (maximum $0.3 \mathrm{ml}$ ) of aquaeus adrenaline $1: 1000$ may be adequate. ${ }^{2}$

TABLE 1. EQUIPMENT AND MEDICATIOII FOR THERAPY OF ANAPHYLAXIS IN OFFICE ${ }^{2}$

\section{Primary}

A. Tourniquet

B. $1 \mathrm{ml}$ and $5 \mathrm{ml}$ disposable syringes

C. Oxygen tank and mask/nasal prongs

D. Epinephrine solution (aqueous) 1:100 0

E. Diphenhydramine injectable

F. Ranitidine or cimetidine injectable

G.Injectable corticosteroids

H. Ambubag, oral airway, laryngoscope, ETT no 12

I. Intravenous set up with large-bore catheter

J. IV fluid: $2000 \mathrm{ml}$ crystalloid, $1000 \mathrm{ml}$ hydroxyethyl starch

K. Aerosol beta-2 bronchodilator 7 compressor nebulizer

L. Glucagon

M.Electrocardiograph

$\mathrm{N}$. Normal saline $10 \mathrm{ml}$ vial for epinephrine dilution

Supporting

A. Suction apparatus

B. Dopamine

C. Sodium bicarbonate

D. Aminophylline

E. Atropine

Optional

A. Defibrilator

B. Calcium

C. Neuroleptic for seizures

D. Lidocain 
Excessive dose of adrenaline can add to patient's distress by causing palpitations, tachycardia, flushing and headache, but cardiac dysrhythmias are rare in otherwise healthy children. When body weight is not known, the dose of adrenaline can be approximated from the child's age (Table 2).

TABLE 2. APPROPRIATE DOSE OF ADRENALINE HCL 1:1000 SOLUTION BASED ON AGE

\begin{tabular}{ll}
\hline Age & Dose \\
\hline $2-6$ months & $0.07 \mathrm{ml}(0.07 \mathrm{mg})$ \\
12 months & $0.1 \mathrm{ml}(0.1 \mathrm{mg})$ \\
$18-48$ months & $0.15 \mathrm{ml}(0.15 \mathrm{mg})$ \\
5 years & $0.2 \mathrm{ml}(0.2 \mathrm{mg})$ \\
6-9 years & $0.3 \mathrm{ml}(0.3 \mathrm{mg})$ \\
10-13 years & $0.4 \mathrm{ml}(0.4 \mathrm{mg})$ \\
$>14$ years & $0.5 \mathrm{ml}(0.5 \mathrm{mg})$ \\
\hline
\end{tabular}

* doses for children between the ages should be approximated ** for mild reaction a dose of $0.3 \mathrm{ml}$ can be considered

Adapted from the Canadian immunization guide 5th edition 1983

Since hypotension is due to a shift of fluid from intravascular to the extravascular space, the mainstay of treatment should be the restoration of intravascular volume. There is debate as to whether colloids or crystalloid should be used and there are arguments to support both form of therapy. ${ }^{6}$ However, the most important of fluid therapy initially is not the composition of the fluid it self, but rather the rate of administration. ${ }^{7}$ Children should receive up to $30 \mathrm{ml} / \mathrm{kg}$ of crystalloid solution in the first hour. ${ }^{8}$

Although fluids are clearly the most important element along with epinephrine in the therapy of hypotension, the use of other vasopressors may also be indicated. However their effectiveness can be diminished since hypotension often occurs in patients who have increased peripheral resistance due to endogenous compensatory mechanisms.

In such patients the hypotension is as noted due to fluid shift and perhaps decreased cardiac output. However vasopressors have been employed for many years and can be helpful. The drug of choice is dopamine administered at a rate of 2 to $20 \mu \mathrm{g} / \mathrm{kg}$ per minute. Any patient requiring dopamine, of course, should be transferred to a tertiary care unit.

\section{Additional measures}

Absorption of vaccine from the injection site can be delayed by physical or chemical means in some instance, to allow time for adrenaline to take effect. When possible a tourniquet can be placed above the vaccination site. It should be released for 1 minute every 3 minutes and stopped as symptoms subside. ${ }^{3}$ If the vaccine was injected subcutaneously, an additional dose of $0.005 \mathrm{ml} / \mathrm{kg}$ (maximum $0.3 \mathrm{ml}$ ) of aqueous adrenaline 1:1000 can be injected into the vaccination site. ${ }^{2,3}$ This is usually reserved for moderate to severe cases and is not repeated. This measure is not appropriate for intramuscular vaccination sites.

\section{Continuing care}

Other medications can be considered to augment or extend the effects of adrenaline but are not essential in areas where patients can be rapidly transferred to a local emergency department for continuing care. All but milder cases will require continuing observation and medication in hospital. Antihistamine therapy can be useful as adjunctive treatment with epinephrine. Although antihistamine therapy is not considered lifesaving, it can at times offer dramatic relief of symptoms. ${ }^{9}$ The exact role of corticosteroids in the management of anaphylaxis has not been established. Patients with severe anaphylactic episodes or patients who had previously been on systemic glucocorticoid therapy within the previous several months should receive corticosteroids.

Perhaps the most salient theoretical rationale for their use relates to their effects on the late phase reaction. Since anaphylaxis can be biphasic, a role for steroids in preventing such a recurrence can be postulated. Suggested intravenous of $10 \mathrm{mg}$ to $100 \mathrm{mg}$ hydrocortisone can be given for severe episodes, and is probably wise to give oral prednisone of $30 \mathrm{mg}$ to 60 $\mathrm{mg}$, to patients who have experienced mild anaphylactic symptoms and been discharged from therapy.

If wheezing unresponsive to epinephrine occurs, aerosolized beta adrenergic agent and if necessary, intravenous aminophylline can be used. With appropriate management, vaccination related anaphylactic reactions almost always have a favorable outcome.

\section{Initial management in non-hospital settings}

Treatment of anaphylaxis by health care providers in non-hospital settings should allow the following steps. 
Firstly call the assistance including an ambulance. Place the patient in a recumbent position, elevating the feet if possible, establish an oral airway if necessary. Promptly administer $0.01 \mathrm{mg} / \mathrm{kg}$ (maximum $0.5 \mathrm{ml}$ ) of aqueous adrenaline $1: 1000$ by subcutaneous or intramuscular injection, in a different limb from that used for vaccination. The subcutaneous route of adrenaline suffices for mild or early cases, while the intra muscular route is preferred for severe cases. Dosing can be repeated at 20 minute intervals or less if necessary, dictated by clinical condition.

Monitor the vital signs and reassess the situation frequently, to guide medication use. Consider adjunctive measures to slow vaccine absorption at the injection site e.g. tourniquet application or to augment the effect of adrenaline. Arrange rapid transport to an emergency unit for further care. All but mildest cases require medication and observation.

\section{References}

1. Lieberman PL. Specific and idiopathic anaphylaxis: Patho- physiology and treatment. In: Bierman CW, Pearlman DS, Shapiro GG, Busse WW, editors. Allergy, asthma and immunology from infancy to adulthood 3rd ed, Philadelphia, WB Saunders; 1996. p. 297-319.

2. Fulginiti VA. Adverse reactions to vaccines: the complexity of vaccine safety, in: Bierman CW, Pearlman DS, Shapiro GG, Busse WW, editors. Allergy asthma and immunology from infancy to adulthood 3rd ed. Philadelphia, WB Saunders 1996. p. 384-91.

3. Scheifele DW. Initial management of anaphylaxis. Vaccines: Children and practice 1999, 2:14-5.

4. Viner NA, Rhany RK. Anaphylaxis manifested by hypotension alone. J Urol 1975; 113:108-12.

5. Popa VT, Lerner SA. Biphasic systemic anaphylactic reaction. The illustrative cases. Ann Allergy 1984, 53:151-5.

6. Shine K, Kuhn M, Young L, Tillisch J. Aspects of the management of shock. Ann Intern Med 1980; 93:723-34.

7. Mueller DL, Noxon JO. Anaphylaxis: pathophysiology and treatment. The compendium 1990, 12:157-71.

8. Saryan JA, O'Louglin JM. Anaphylaxis in children. Pediatr Ann 1992, 21:590-8.

9. Yarbrough JA, Moffit JE, Brown DA, Stafford CT. Cimitidine in the treatment of refractory anaphylaxis. Ann Allergy 1989, 63:237-8. 